\title{
Interdisciplinary Approach (S.T.E.M.) of the Rotational Motion of Solids Bodies: A Comparative Study
}

\author{
Georgios Kalantzis ${ }^{1}$, Charilaos Tsihouridis ${ }^{2}$, Marianthi Batsila ${ }^{3}$ and Dennis Vavougios ${ }^{4}$ \\ ${ }^{1}$ Directorate of Secondary Education- PhD Candidate \\ Department of computer science and telecommunications University of Thessaly \\ Lamia, Greece \\ Email:gkalantzis [AT] uth.gr \\ ${ }^{2}$ University of Patras, Greece \\ Patras, Greece \\ Email: hatsihour [AT] upatras.gr \\ ${ }^{3}$ University of Thessaly, Greece \\ Lamia, Greece \\ Email: marbatsila [AT] uth.gr \\ ${ }^{4}$ University of Thessaly, Greece \\ Lamia, Greece \\ Email: dvavou [AT] uth.gr
}

\begin{abstract}
The present paper explores issues concerning Senior High School students' teaching and understanding of concepts and laws, related to the rotation of a solid body around a fixed axis of rotation, through a properly designed experimental type of teaching intervention, that incorporates custom-made educational material and utilizes ICT. Through an interdisciplinary-exploratory approach of teaching, the alternative ideas of 143 high school students, aged 16-17, were initially identified. The students were divided into a control group and an experimental one and completed a suitably designed questionnaire before and after the didactic interventions. The interventions aimed at investigating the extent to which the experimental student group alternative ideas, taught through an experimental scientific approach, changed compared to the ideas of the students of the control group, who were taught the same subjects in a conventional way. The results, obtained from a quantitative and qualitative analysis of questionnaires and interviews, indicate an improvement of the experimental student group understanding, in relation to the concepts of rotational movement. Additionally, they indicate the development of a positive attitude towards the experimental procedure, applied throughout the intervention, as opposed to that of the control group, where the teaching was carried out in a conventional way.
\end{abstract}

Keywords—Experimental Physics teaching, ICT in Physics teaching, Rotational motion teaching, Raspberry Pi, STEM

\section{INTRODUCTION}

Before formal instruction begins, students come to class with a variety of ideas, formed through their day-to-day experiences (Widodo, Duit \& Müller, 2002). These ideas are generally intuitive and/or simplistic as opposed to scientific ones (Lautrey \& Mazens, 2004, Clement, Brown \& Zeitsman, 1989). In science teaching literature, these ideas are characterized as alternative and are particularly important because they shape and influence students' future learning and consequently physics learning (Özmen, 2005, Ausubel, 1963, Gagne 1965).

One of the most crucial points in the understanding of Physics, taught to Junior and Senior High School level students, is that of the connection between power and movement (Carvalho \& Sousa, 2005) and the study of the way it is approached by learners, constituting a particularly important goal for teachers (Robinson, 2014). The concepts of force and motion are related to Newton's laws, the understanding of which has been studied in detail, in relation to the metaphorical motion, in the context of the Physics didactics research. It should be noted, however, that there is a small number of research papers in the international literature that refer to rotational motion and its dynamics and the role of the moment of inertia and scrolling, despite the fact that they are particularly difficult concepts for students to understand (Mashood \& Singh, 2012; Kladivova \& Mucha 2014). The main points of specific surveys, related to the relevant areas, are briefly discussed below: 
The results of a study of students' alternative ideas about the concept of torque revealed that students believe that: "every force acting on an object produces torque..." and also "...'torque is the same as 'force' and has the same direction...." (Klammer, pp.31,1998).

Rimoldini and Singh (2005) explored undergraduate University students' alternative ideas for the concepts of scrolling, rotational motion, and torque. They concluded that students had difficulty understanding the concept of torque and were generally confused with the concepts of force and torque. They also noticed that some students did not understand the role of torque in the changes of the angular velocity and acceleration.

In their paper, Sarığlan \& Küçüközer (2013) aimed at exploring 10th graders' alternative concepts of torque, angular momentum conservation and Kepler's second law of motion, using questionnaires, with open-ended questions. Their research concluded that students' pre-existing perceptions regarding torque and angular momentum were opposed to the scientifically accepted ones. Furthermore, students also had alternative ideas for angular momentum conservation and Kepler's second law.

Duman, et al. (2015) studied Primary Education University Department graduates' alternative ideas and difficulties of understanding the concepts of scrolling, rotational movement and torque. The analysis of their questionnaire data indicated that there was no statistically significant difference in the responses of male and female learners, in relation to previously examined concepts.

Pranata, et al. (2017) examined the degree of Senior High School students' understanding of the concepts of rotational movement with the help of an interactive simulation, assisted by a free body diagram (Tanang et al., 2014), a questionnaire and a worksheet, specifically designed for it. Among other things, the researchers came into the conclusion that students: found it difficult to define the concept of force in complex rotating systems, tended to believe that the upward force usually has a positive torque and, vice versa, and knew that the moment of inertia of an object is affected by its mass and radius but found it difficult to refer to this. Finally, they had difficulty determining constants and variables when applying Newton's second law to rotational motion in the presence of torque.

According to other researchers, students confront difficulties in determining how the force acts when a body rotates (Rimoldini \& Singh, 2005; Mashood \& Singh, 2012; 2015; Close, et al., 2013) and in explaining the way that the distribution of mass of the rotating body affects its motion, as expressed through the moment of inertia (Leyvraz, 2015).

Rimoldini \& Singh (2005) compared two groups, the first of which consisted of university students, while the second group of high school learners. All participants experienced similar difficulties, regardless of their background, whereas the higher mathematical complexity of the first group did not appear to have helped them to gain a deeper understanding. The authors also found that some of the difficulties were due to the fact that, in rotational motion, participants used concepts with a deeper reference to linear motion, while some other difficulties were due to the complex nature of the rotational motion.

Close et al. (2013) asked students to compare the metaphorical motion of similar solids that differed only in the point of application of the force. The researchers pointed out that the prevailing view among students is that the forces that cause rotational motion have a reduced effect on metaphorical motion, as well as that the force contributes, partly, to rotational motion. The researchers linked this to the way Newton's second law of rotational motion, as a rotational analog of the first law, is presented in textbooks.

Rafon \& Mistades (2020) investigated the effectiveness of the application of the flipped classroom teaching model and the $5 \mathrm{E}$ model in the teaching of rotational movement to high school students, using a STEM approach. They found that these have a positive effect on the factors evaluated in a STEM type didactic approach but also in the understanding of natural concepts.

Khasanah et al. (2016) studied the evolution of students' mental models for the concepts of rotational motion. The researchers observed that the solution strategies that students choose seem to depend on the form of representation with which problems are introduced (De Cock, 2012). The complex problem chosen by the researchers concerned the dynamics of the rotational motion. The researchers watched the students in their attempt to improve their original mental models in order to finally arrive at a scientifically accepted mental model. The results showed that students of different grades have the same initial difficulties in terms of the concepts of rotational movement and rolling.

In their work, Luchembe \& Shumba (2019) explored the problems undergraduate students faced in understanding the concepts of physics, related to circular and rotational motion. They proposed a method to improve comprehension that combines practical work, PhET simulations, and a systematic feedback process, following the model of Nicol \& Macfarlane-Dick (2006). The researchers found that this approach improves students' learning of circular and rotational motion.

Adbisa \& Getinet (2012) studied the effectiveness of teaching methods and the extent to which they contribute to improving students' understanding in general and rotational movement in particular. Their sample consisted of 11 th graders 
from three Ethiopian schools, to whom they introduced the concept of rotational movement through guided discovery, presentation-based teaching, and conventional teaching techniques. Their research results showed that the most effective of all were the teaching interventions that used guided discovery, while teaching through presentations came second in place as a method. The researchers pointed out that there is a strong correlation between students' achievement of comprehension and cognitive background and this result is independent of the teaching method. Additionally, there was no statistically significant difference between boys and girls in terms of comprehension.

From a different perspective, physics researchers and physics teachers have hypothesized that students do not use their personal alternative ideas at school. Instead, they use ways through which they observe the world and talk about it, and which are essentially related to the community they belong to (Matron, 1984, Lemke, 1990, Ueno 1990, Roth, 1995). This hypothesis leads to the observation that, since particularly interesting interactions of science take place in students' daily spoken exchanges, and regardless of the way they may approach learning, teachers should be aware of the way their students argue, as well as the kind of arguments they use, in order to help them form scientific discourse. However, this has rarely happened in the past (Lemke 1990, Roth 1995). In this perspective, Roth et al., (2001) presented the results of two of their research efforts, in which they examined students' speech and arguments, used for the observation and interpretation of phenomena, involving concepts related to rotational motion. The findings of the first study showed that, despite their pre-existing teaching, students' descriptions of rotational phenomena differed from the scientifically accepted ones and were incompatible with the context in which they were taught. The second study highlighted the variations in students' arguments about rotational motion and their difference from scientifically accepted arguments. Overall, it seems that only a small minority of students could give descriptions of the dynamics of rotational motion that were sufficient in terms of scientifically acceptable descriptions.

In his doctoral thesis, Mashood (2014) presents the development and evaluation of a psychometric tool (concept inventory) to explore concepts of rotational motion, as perceived by Senior High School students. The purpose of the tool was to explore students' difficulties and alternative perceptions through a selected set of multiple-choice questions (items). The answers to these questions allowed the emergence of reasoning patterns which were obviously not in accordance with the scientifically acceptable ones (Singh, 2011). The questionnaire was divided into three sections. The first part concerned the rotational motion of a particle (Mashood \& Singh, 2012a). The second part referred to the kinematics of rotational motion (Mashood \& Singh, 2012b, 2012c). Finally, the third part examined students' perceptions and reasoning about the rotational motion of a solid body around a fixed axis of rotation (Mashood \& Singh, 2014). Mashood (2014) found that, regarding rotational motion, students: “.... have difficulty understanding the directions of angular velocity and acceleration, as these are opposing to their intuition. They have the idea that angular velocity mimics the behavior of angular acceleration. They lack knowledge about when to apply the equations that connect: velocity to angular velocity and position, acceleration to angular acceleration and position, moment to moment of inertia and angular acceleration. They are reluctant to determine angular quantities when the trajectory of motion is straight". The final conclusion of Mashood's research was that, among the students who were the sample of the research, there was a constant predominance in their thinking of interpretive models that are not scientifically acceptable. One of the most important points of the research is the fact that part of the questionnaire was given to students of the University of Washington. The result of the analysis showed that there is an analogy between the models used by the students of that University with those of the students who participated in his research.

Technology, engineering, and mathematics - STEM - are becoming especially important cognitive fields today. These fields relate to upcoming and modern trends of educational systems that place an emphasis to them, aiming at their effective teaching (Tsihouridis et al., 2013, Tsihouridis et al., 2014). According to Wang et al. (2011), the epistemological content of STEM is based on the interdisciplinary teaching approach, which places each subject within a broader cross-curricular framework, where the mathematical "literacy" has a key role. Each subject is approached in an interdisciplinary way and in a broader context where, as in the case of this research, Science, Mathematics and Informatics and their application in dealing with and solving specific daily problems that arise, play an important role. Yuliati et al. (2018) highlights the positive contribution of STEM education in learning and understanding concepts and phenomena of physics.

This paper explores issues related to Senior High School students' teaching and understanding of concepts and laws related to the rotation of the solid body, around a fixed axis of rotation. This is done through a properly designed experimental type of teaching intervention, that incorporates custom-made educational material and utilizes ICT approaches with positive learning results (Tsihouridis et al., 2009, Tsihouridis et al., 2011). The teaching intervention here is based on an interdisciplinary-exploratory S.T.E.M type approach to teaching.

\section{THE RESEARCH}

\subsection{The Purpose of the Research-The Research Questions}

The research aimed:

- To explore the initial ideas of high school students (aged 16-17 years) regarding the concepts related to rotational 
movement

- To compare the effectiveness of this didactic intervention, which is based on an interdisciplinary-exploratory S.T.E.M type teaching approach, to a conventional type of a didactic intervention, implemented following the guidelines of the school curriculum.

- To test whether alternative ideas can change to scientifically accepted ones, with the help of a specially designed teaching intervention that utilizes a custom-made experimental device and ICT.

In particular, the present paper will compare the learning outcomes that result after the implementation of the teaching intervention to Senior High School students, in terms of understanding concepts and laws related to the rotation of the solid body, around a fixed axis of rotation. This will be in the context of an exploratory, hands-on didactic intervention (experimental group), and compared to the respective learning outcomes of students of the same classes, who were taught the same subjects with conventional teaching (control group).

\section{Interdisciplinary Teaching Intervention Design (S.T.E.M.)}

Hsu \& Fang (2019) define STEM education as an educational approach in which, the content related to the subjects is referred to a) as a group of individual ideas (multidisciplinarity) or b) as ideas integrated with problem solving (crosscurricular or interdisciplinary approach). Based on Wang et al., (2011) the epistemological content of STEM is based on the interdisciplinary teaching approach, which places each subject within a broader cross-curricular context, in which mathematical "literacy" has a basic role. According to Abdullah, et al. (2014) students who acquire problem-solving skills can analyze data by producing new information while, at the same time, improve their reasoning ability and creativity. When this cooperation takes place within a group, students not only acquire knowledge, but they also experience positive emotions towards the other members of the group, as they are trained within a social context, thus, gaining greater selfawareness, self-esteem and self-confidence.

\subsection{Scientific and Mathematical Approach to Hollow Cylinder Rotation}

The present study will look at the case of the hollow cylinder and the concepts of rotational motion, as this rotates around an axis of rotation, passing through the centers of its bases, finally focusing on calculating its moment of inertia. The theoretical calculation of torque is given by the relation: $I_{\theta}=\frac{1}{2} \cdot M \cdot\left(R_{1}^{2}+R_{2}^{2}\right)$ (1)

where: $\mathrm{M}$ is the mass of the cylinder and $\mathrm{R}_{1}$ and $\mathrm{R}_{2}$ the radii of the outer and inner circles respectively.

Calculation of the moment of inertia of a hollow cylinder, based on the custom-made experimental device. Physics and mathematical approach.

Figure 1 shows the schematic representation of the hollow cylinder rotation as well as the cross section of the schematic representation of the experimental device used in the research.

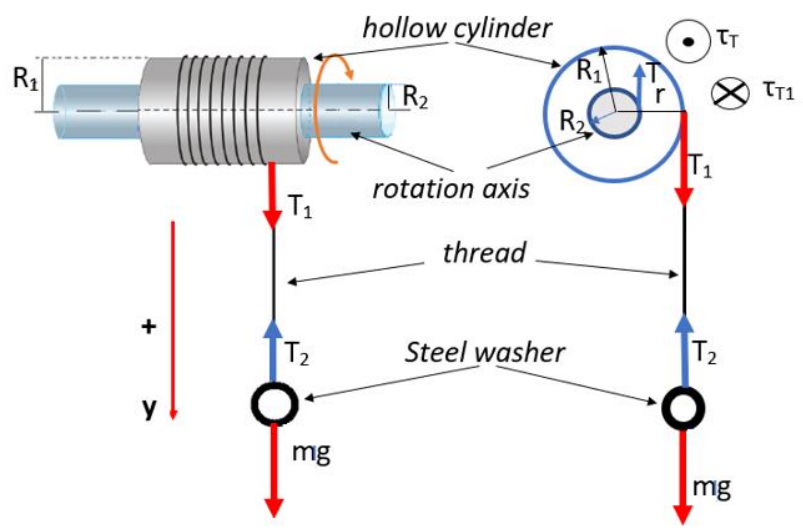

(a)

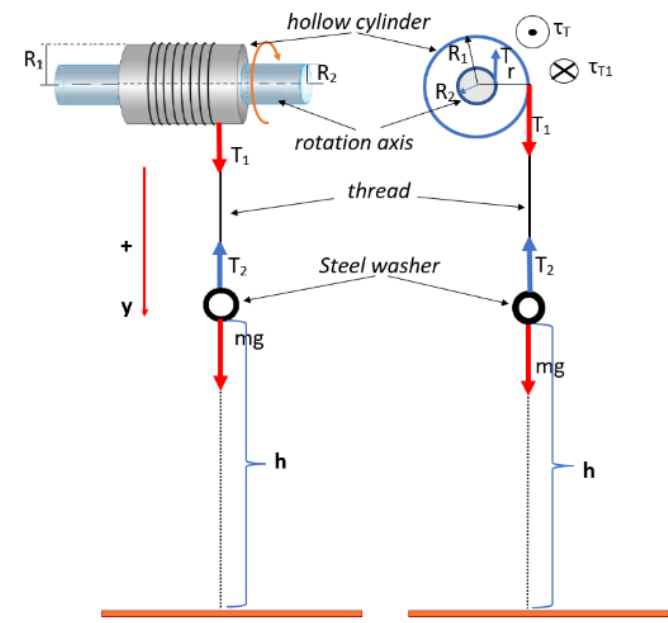

(b)

Figure 1: Schematic representation of the experiment and cross section of the schematic representation

This phenomenon comes in two phases: the phase of the accelerated rotational motion of the hollow cylinder, during the fall of the washer and the phase of the decelerating rotational motion that follows, due to the absence of the torque of the force that causes the rotation of the solid.

For the accelerated phase of the solid: 
Body movement (washer mass m) (fig. 1)

As the washer mass $m$ is released to fall (considering the friction and air resistance as negligible), the following mathematical relations apply:

For the body (washer) m: $\Sigma F_{y}=m \cdot a \Leftrightarrow m \cdot g-T_{2}=m \cdot \alpha \Leftrightarrow T_{2}=m \cdot g-m \cdot \alpha=m \cdot(g-\alpha)(2)$

For the cylinder: $\quad \Sigma \tau=I_{\pi} \cdot \boldsymbol{a}_{1} \Leftrightarrow T_{1} \cdot R_{1}-T \cdot R_{2}=I_{\pi} \cdot \boldsymbol{a}_{1}(3)$

Where: $\mathbf{R}_{1}$ : outer radius of the hollow cylinder, $\mathbf{R}_{\mathbf{2}}$ : radius of the cylindrical axis of rotation (inner radius of the hollow cylinder), $\mathbf{T}_{\mathbf{1}}$ : the tension of the thread at the point with the roller, $\mathbf{T}_{2}$ : the tension of the thread at the point with the washer, $\mathbf{T}$ : the friction between the hollow cylinder and the axis of rotation, $\boldsymbol{\alpha}:$ the numerical value of the linear acceleration of the washer, $\boldsymbol{\alpha}_{\mathbf{1}}$ : the numerical value of the angular acceleration of the rotating solid, when accelerated during the fall of the washer, $\boldsymbol{\alpha}_{2}$ : the numerical value of the angular acceleration of the rotating solid, when it decelerates after the fall of the washer, $\boldsymbol{\Sigma}_{\mathrm{T}}$ : the algebraic sum of the numerical values of the vectors of the torques exerted on the system (it makes sense because moments of the same direction are exerted), $\boldsymbol{\tau}_{\mathrm{T}}$ : T friction torque, $\boldsymbol{\tau}_{\mathrm{T} 1}$ : force torque $\mathrm{T}_{1}, \mathbf{I}_{\pi}$ : the experimental value of the moment of inertia of the body-system, m: Washer mass, M: Hollow cylinder mass, $\mathbf{g}$ : Acceleration of gravity (value $9,80655 \mathrm{~m} / \mathrm{s} 2$ based on the literature), h: distance of the washer from the ground, t: time of the washer falling from height h.

Because $T_{1}=T_{2}$ (we consider that the thread has a negligible mass and constant length), the above relation with the help of (2) becomes: $m \cdot(g-\alpha) \cdot R_{1}-T \cdot R_{2}=I_{\pi} \cdot \boldsymbol{a}_{1}(4)$

Additionally, it applies: $\alpha=\boldsymbol{a}_{1} \cdot R_{1}(5)$

The calculation of the numerical value of the angular acceleration $\boldsymbol{\alpha}_{1}$ of the rotating solid, when it accelerates during the fall of the washer, can also be done from the time of the fall of the washer from height $\mathrm{h}$ (2nd approach, fig. 1b)

It applies, $\mathrm{h}=\frac{1}{2} \cdot a \cdot t^{2} \Rightarrow \alpha=\frac{2 \cdot h}{t^{2}} \kappa \alpha 1 \quad \alpha=\boldsymbol{a}_{1} \cdot R_{1} \Leftrightarrow \boldsymbol{a}_{1}=\frac{2 \cdot h}{R_{1} \cdot t^{2}}(6)$

For the decelerating rotational motion of the solid:

For the torque of the frictions $\tau_{\mathbf{T}}$ will apply:

$\tau_{T}=T \cdot R_{2}=I_{\pi} \cdot\left|\boldsymbol{a}_{2}\right|$

So, the relation (4) with the help of (5) becomes:

$m \cdot(g-\alpha) \cdot R_{1}-T \cdot R_{2}=I_{\pi} \cdot \boldsymbol{a}_{1} \Leftrightarrow m \cdot(g-\alpha) \cdot R_{1}-I_{\pi} \cdot\left|\boldsymbol{a}_{2}\right|=I_{\pi} \cdot \boldsymbol{a}_{1} \Leftrightarrow m \cdot(g-\alpha) \cdot R_{1}=I_{\pi} \cdot a_{1}+I_{\pi} \cdot\left|\boldsymbol{a}_{2}\right| \Leftrightarrow$ $m \cdot(g-\alpha) \cdot R_{1}=I_{\pi} \cdot\left(a_{1}+\left|\boldsymbol{a}_{2}\right|\right)$

And we result in: $I_{\pi 1}=\frac{m \cdot(g-\alpha) \cdot R_{1}}{\boldsymbol{a}_{1}+\left|\boldsymbol{a}_{2}\right|}=\frac{m \cdot\left(g-\boldsymbol{a}_{1} \cdot R_{1}\right) \cdot R_{1}}{\boldsymbol{a}_{1}+\left|\boldsymbol{a}_{2}\right|}$

Based on the relation (6), (8) becomes:

$\boldsymbol{I}_{\boldsymbol{\pi} \mathbf{2}}=\frac{m \cdot\left(g-\frac{2 \cdot h}{t^{2}}\right) \cdot R_{1}}{\frac{2 \cdot h}{R_{1} \cdot t^{2}}+\left|\boldsymbol{a}_{2}\right|}$ (9)

Based on the relations (8) and (9), the experimental determination of the moment of inertia of the hollow cylinder can be done (all the values of the relation are measured or calculated experimentally, value $\mathrm{g}=9.80655 \mathrm{~m} / \mathrm{s} 2$ ) in two ways.

Finally, by comparing the two moments of inertia (theoretical and experimental), we can calculate the deviation at $\%$ with the following formula.

$$
I(\%)=\left|\frac{I_{\pi}-I_{\vartheta}}{I_{\vartheta}}\right| \times 100 \%
$$

\subsection{Engineering Approach to Hollow Cylinder Rotation. The Experimental Device}

The experimental device consists of a suitable base, on which a rotating shaft is mounted. Hollow cylinders of different materials can be fitted on it (in our case: wood, plastic and aluminum, fig.2) which, after the initial pushing, can be rotated for a long time with (almost) constant angular velocity. On each cylinder, a neodymium magnet is fitted. Its motion is detected by a Hall Effect sensor. This is essentially an angular velocity sensor connected to a Raspberry Pi system that receives the measurements which are then automatically entered in the Libre Office (fig.3). It is essentially a self/custommade experimental device assembled by the participants, providing them (the students) with experiential experience at all stages. The device is low cost and is characterized by sufficient reliability of the measurements taken 

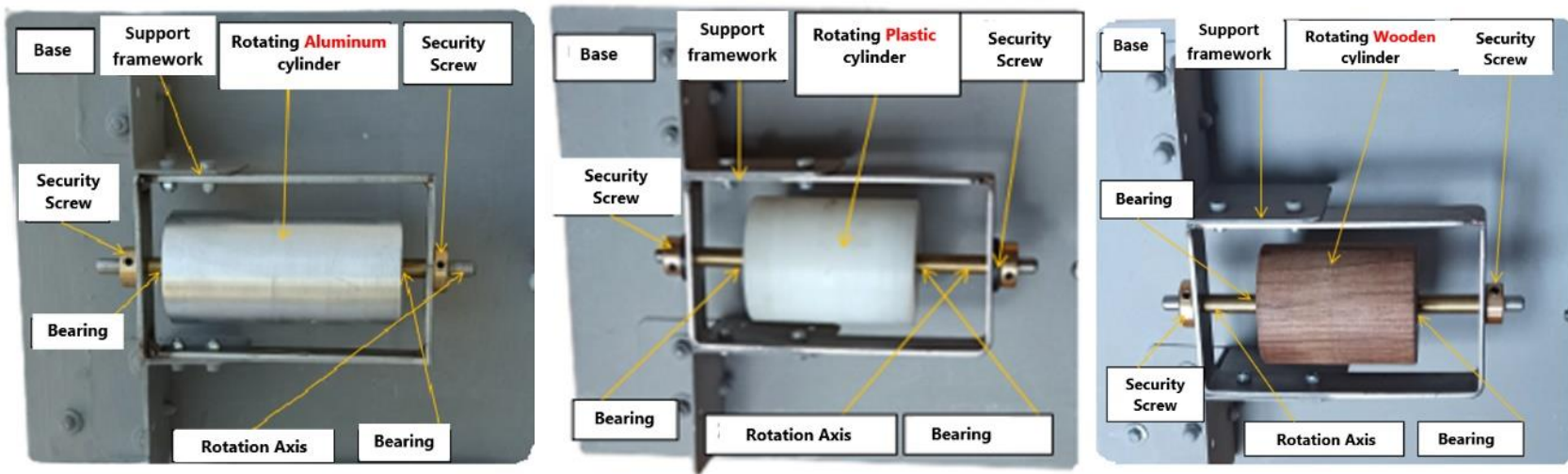

Figure. 2. The experimental rotation device of the various cylinders studied (Aluminum, Plastic, Wooden)

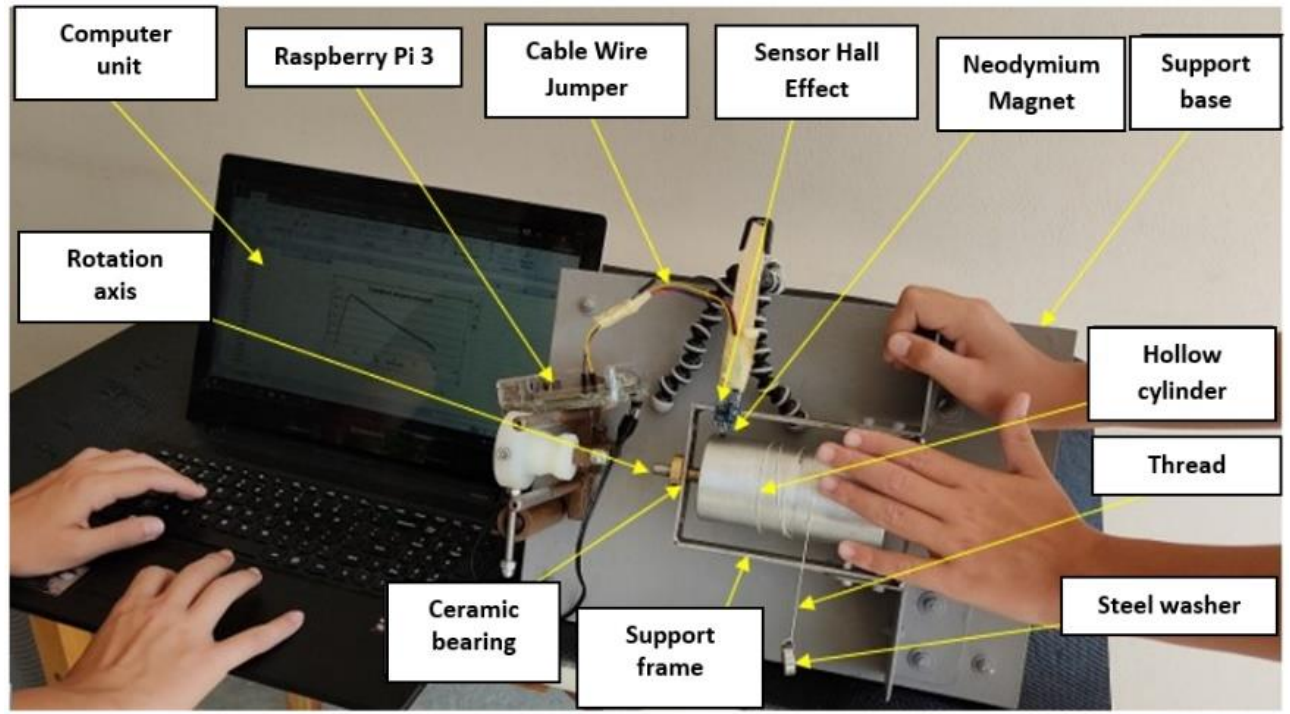

Figure. 3. The experimental device used to study the rotational motion of the hollow cylinder

\subsection{Technological Approach. Sensor Connection and Use of Raspberry Pi Computer/Programming Device - Data Visualization}

The experimental set up consists of the experimental device, which in our case is the rotating solid, the Raspberry Pi 3, a hall Effect sensor (it is a type of sensor that detects the presence and size of a magnetic field), a rectangular neodymium magnet of rectangular diagonal (mm) $3 \times 1 \times 1$ and the laptop. The sensor is mounted on a base that we will hereinafter call the sensor base and is connected to the Raspberry Pi. The sensor base and the Raspberry Pi are in turn adapted to the base of each experimental device (fig.4).

In order to measure the angular velocity, we had to create a program that would run in the Pi environment. We chose to create it using the Python language.

The program should enable us to simultaneously perform actions 2 and 3 above, i.e., to create the file and to have the visual representation. 


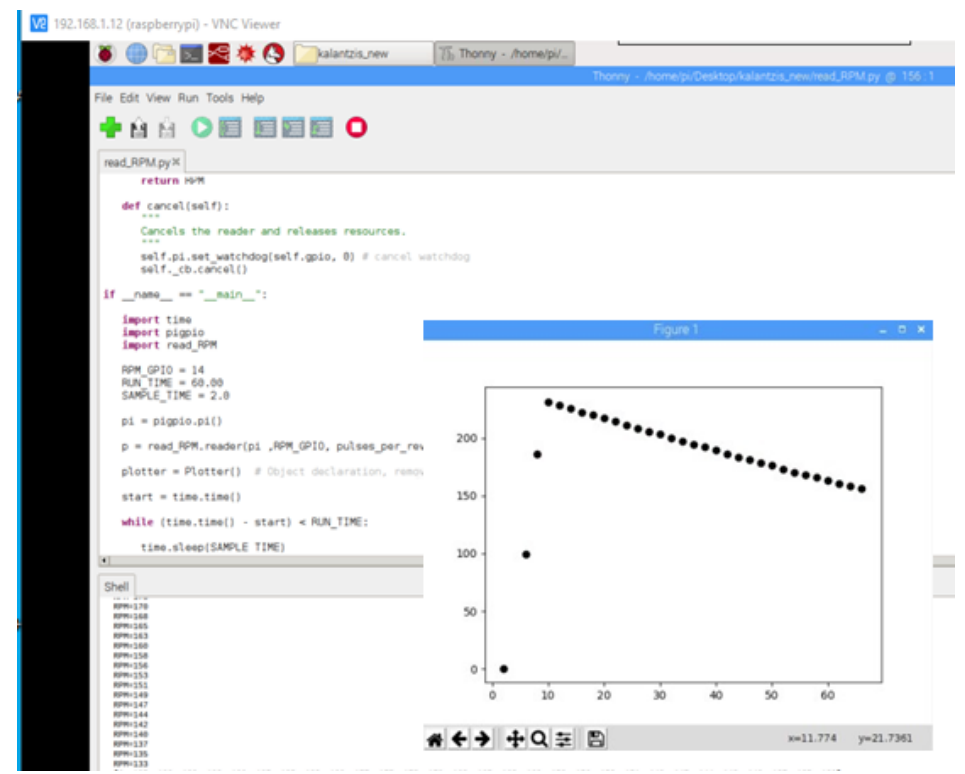

Figure. 4: The Raspberry Pi program and the visualization of the measurements.

\section{THE IMPLEMENTATION OF THE TEACHING INTERVENTION}

\subsection{The Sample}

The sample consisted of 143 students deriving from four different Senior High Schools. The selection of the participants was done with the technique of proportionate stratified sampling (Cohen et al., 2008). The experimental group (EG) and the control group (CG) were formed by drawing and the data are presented in Table 1 below. The experimental group consisted of 84 students and the teaching was carried out with the experimental set up, while the control group consisted of 59 students and the teaching was carried out in the conventional way, as determined by the syllabus.

Table 1: The experimental and the control groups

\begin{tabular}{|l|l|l|c|}
\hline & \multicolumn{1}{|c|}{ Teaching Approach } & \multicolumn{1}{|c|}{ Group Code } & Number of students \\
\hline 1 & Teaching in a conventional way & Control Group (CE) & 59 \\
\hline 2 & Teaching using an interdisciplinary STEM approach & Experimental Group 1 (EG.1) & 84 \\
\hline & & TOTAL & 143 \\
\hline
\end{tabular}

\section{2 The Implementation}

The students in both the control group and the experimental group worked in teams of 2-3 people. Before conducting the research, the students of the experimental group became familiar with the experimental setup and the taking of the measurements. The purpose of the activities, during the implementation of the didactic intervention, was the experimental measurement of the moment of inertia of the three hollow cylinders and their comparison with the theoretical way of calculating the moment of inertia of a hollow cylinder. During the experiment, the participants had the opportunity to reflect and study the concepts and laws, related to the rotational motion of a solid body, that in this case were: the axes of rotation, the angular velocity, the angular acceleration, the fundamental law of rotational motion, the equilibrium and motion of a solid body around an axis of rotation, and finally the moment of inertia, the kinetic energy in rotational motion.

The participants in the experimental group determined the moment of inertia in two different ways. According to the first way, these students were divided into ten (10) groups. The members of each group took five (5) measurements for each rotating solid where the average of their measurements was the first measurement of the Group. Afterwards, each group processed the data and calculated the moment of inertia of the cylinder. In this way ten (10) measurements were taken for each solid and a total of 30 measurements for the three custom/self-made devices. In the second way, the participants in each group took measurements that were automatically registered in the Libre Office, with the help of the 
angular speed sensor and the Raspberry $\mathrm{Pi}$, and the result was again processed and exported. In addition, there was a visualization of the angular velocity graph over time with the help of the Raspberry Pi (Figure 3) and the use of an appropriate program in the Python programming language.

Throughout the teaching intervention, the students worked with an appropriate worksheet, following the structure of a specific teaching scenario, based on the research evolving teaching model, which is compatible with an interdisciplinaryexploratory S.T.E.M type approach to teaching. In this context, the participants in the experimental group formulated hypotheses, worked with the data, compared their results and in combination with the theoretical way of calculating the moment of inertia of a hollow cylinder, came to conclusions, taking advantage of the possibilities they were offered to use the technology.

The final result of the processing of the averages of the thirty measurements, (10 for each solid) for the three types of the hollow cylinders, are presented in summary in Table 2 and are visualized in Figure 5 that follows.

Table 2: Aggregate Experimental data and results of their processing

\begin{tabular}{|c|c|c|c|c|c|c|c|c|c|c|}
\hline $\begin{array}{l}\text { Rotating } \\
\text { cylinder } \\
\text { type }\end{array}$ & $\begin{array}{l}\text { Equation of } \\
\text { accelerated } \\
\text { rotational } \\
\text { motion }\end{array}$ & $\begin{array}{l}\text { Equation of } \\
\text { decelerating } \\
\text { rotational } \\
\text { motion }\end{array}$ & $\begin{array}{c}\text { Angular } \\
\text { acceleratio } \\
\mathbf{n} \\
\boldsymbol{\alpha}_{1} \\
\left(\mathrm{rad} / \mathbf{s}^{2}\right)\end{array}$ & $\begin{array}{c}\text { Angular } \\
\text { deceleration } \\
\alpha_{2}\left(\mathrm{rad} / \mathrm{s}^{2}\right)\end{array}$ & $\begin{array}{c}\text { Washe } \\
\text { r drop } \\
\text { time } \\
\text { t(s) } \\
\text { averag } \\
\text { e }\end{array}$ & $\begin{array}{c}\text { Moment } \\
\text { of inertia } \\
\mathbf{I}_{(\mathbf{t h})} \\
\mathbf{x 1 0} \\
\mathbf{k g} \cdot \mathbf{m}^{\mathbf{2}}\end{array}$ & $\begin{array}{c}\text { Moment } \\
\text { of } \\
\text { inertia } \\
\mathbf{I}_{\exp (1)} \\
\mathbf{x 1 0}{ }^{-4} \\
\mathrm{~kg} \cdot \mathbf{m}^{2}\end{array}$ & $\begin{array}{c}\pi_{(1)} \\
\% \\
\text { erro } \\
\mathbf{r}\end{array}$ & $\begin{array}{c}\text { Moment } \\
\text { of } \\
\text { inertia } \\
\mathbf{I}_{\exp (2)} \\
\mathbf{x 1 0} \\
\mathbf{k g} \cdot \mathbf{m}^{\mathbf{2}}\end{array}$ & $\begin{array}{c}\pi_{(2)} \\
\% \\
\text { error }\end{array}$ \\
\hline $\begin{array}{c}\text { Plastic } \\
\text { hollow } \\
\text { Cylinder }\end{array}$ & $\begin{array}{c}\mathrm{y}=19,137 \mathrm{x}+ \\
16,061\end{array}$ & $\begin{array}{c}y=-0,656 x+ \\
47,526\end{array}$ & 19,137 & $-0,656$ & 2,552 & 1,4931 & 1,5259 & 2,20 & 1,4818 & 0,76 \\
\hline $\begin{array}{l}\text { Aluminu } \\
\text { m hollow } \\
\text { Cylinder }\end{array}$ & $\begin{array}{c}y=7,777 x+ \\
16,956\end{array}$ & $\begin{array}{c}y=-0,233 x+ \\
31,886\end{array}$ & 7,777 & $-0,233$ & 4,0073 & 4,0075 & 3,9442 & 1,58 & 3,9396 & 1,70 \\
\hline $\begin{array}{l}\text { Wooden } \\
\text { hollow } \\
\text { Cylinder }\end{array}$ & $\begin{array}{c}\mathrm{y}=35,510 \mathrm{x}+ \\
19,838\end{array}$ & $\begin{array}{c}y=-1,204 x+ \\
67,662\end{array}$ & 35,51 & $-1,204$ & 1,9252 & 0,8015 & 0,7732 & 3,53 & 0,8006 & 0,11 \\
\hline
\end{tabular}

From the analysis of the experimental data of the ten (10) measurements, we observe that the minimum value of the deviation of the experimentally calculated value of the moment of inertia from the theoretically calculated value is:

$\alpha$ ) For the case of calculation of the angular acceleration $\alpha 1$ of the rotating solid from the slope of the line of the diagram $\omega(\mathrm{t}): 0.07 \%$ (plastic cylinder) in absolute value and the maximum value $7.36 \%$ (wooden cylinder) in absolute value, with the value range by absolute value of the deviation being at $7.29 \%$

$\beta$ ) For the case of calculation of angular acceleration $\alpha 1$ of the rotating solid of the relation from the time of falling of the washer $\mathrm{t}$ from height h: $0,33 \%$ (plastic cylinder) in absolute value and the maximum value 6,29\% (wooden cylinder) in absolute value, with the value range by absolute value of the deviation being at $5.96 \%$.

The deviations are considered very satisfactory for both cases, showing the reliability of the whole experimental device for calculating the moment of inertia of hollow cylinders of different materials and consequently the study of the whole phenomenon of rotational motion of solids. 


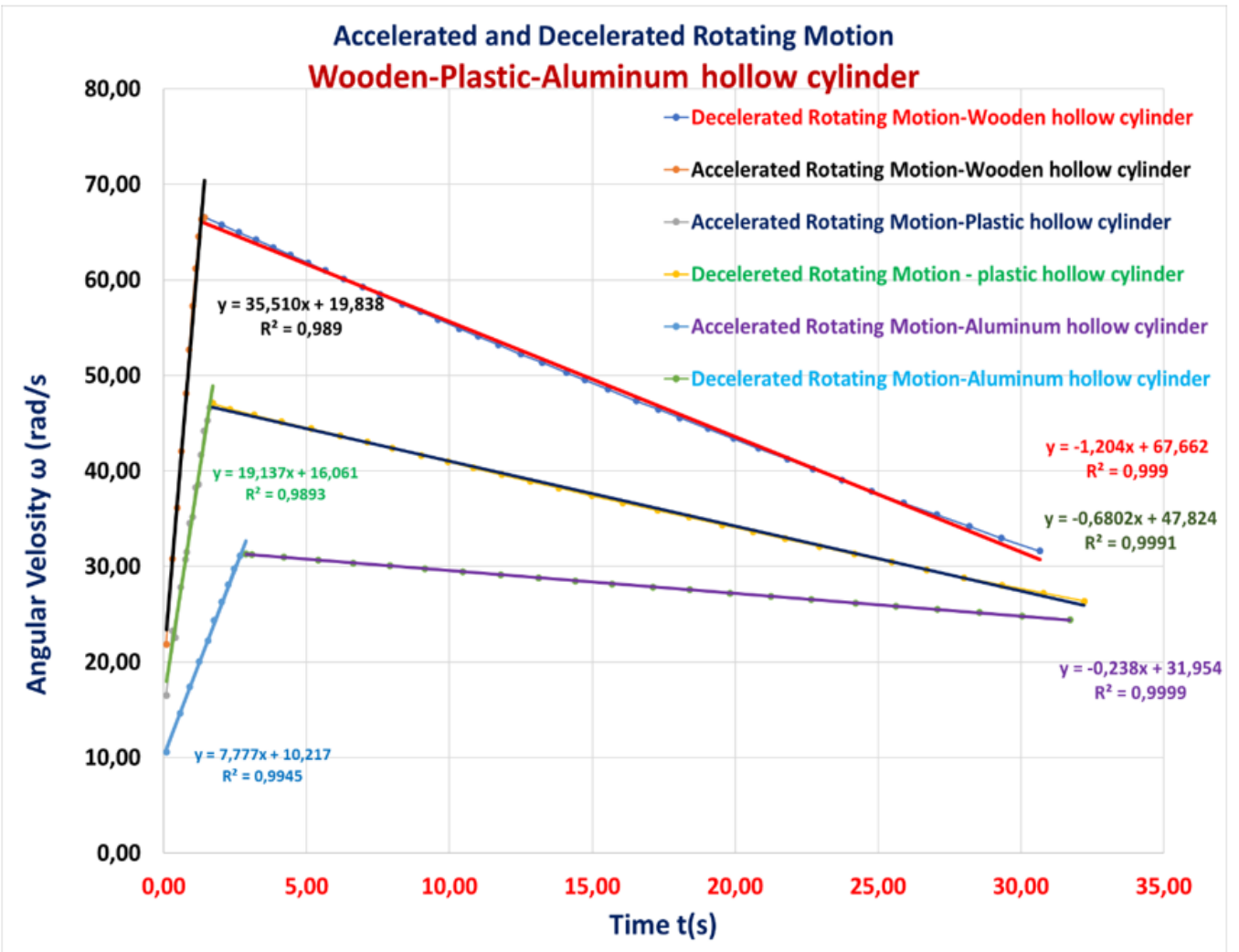

Figure. 5: Common diagram of the angular velocity-time graphs of all three cylinders during their rotational motion.

We observe that all the experimental data for the different types of cylinders correspond very well to the study of rotational motion. This results from the above diagram where the trend line of the points in the diagram $\omega(\mathrm{t})$, in both accelerated and decelerated rotation of the rollers, are straight with an adjustment factor of $0.989-0.995$ in accelerated motion and 0.999 in decelerated motion. From the very good fit of the trend line, the values of the angular acceleration $\alpha 1$ and the angular deceleration $\alpha 2$ result from the respective inclinations of the lines (lines) in diagram $\omega(\mathrm{t})$.

\section{3 Data Collection Tools}

For the purposes of this study and in order to find possible answers to the research questions, a questionnaire was given to both groups, the same before and after the teaching interventions. Especially for the experimental team, a focus group with twelve randomly selected students from the EG was formed, with whom all aspects of the intervention process were discussed.

The questionnaire, designed for the needs of the research, included forty-two (42) questions in its pilot phase. After processing the answers of the participants in order to improve it, thirty-two (32) questions remained in the final version which were used in the main research. The main research questionnaire was checked for content validity, structural validity, reliability, internal consistency and synchronous validity. The reliability (and validity) of the questionnaire were mainly tested using a pre-testing evaluation. The statistical analysis was done with the Statistical Package for Social Sciences (SPSS) for which the University of Thessaly is a legal user, as well as with a suitable program in Excel. The analysis of the results gave the reliability of the questionnaire in terms of its internal coherence and its structural validity values for the Cronbach coefficient $\alpha$, for the pre-test $\mathrm{a}=0.809$ and for the post-test $\mathrm{a}=0.812$. It should be stressed here again that, during the research, the qualitative data, collected from the focus group, were used to support the quantitative data.

Table 3 below shows the main categories of the subject and their subcategories in relation to the respective questions (items), as these were used to analyze the answers in the questionnaires.

In the context of the questions analysis, we investigated the rotation of a solid body through a questionnaire and the questions were categorized into seven main axes and thirteen secondary axes, as shown in Table 2 below. 
Table 3: Categories and subcategories of the teaching objectives

\begin{tabular}{|c|c|c|}
\hline Categories of teaching objectives & Subcategories & $\begin{array}{l}\text { Question } \\
\text { number }\end{array}$ \\
\hline \multirow{6}{*}{$\begin{array}{l}\text { O1. Characteristic quantities of the } \\
\text { rotational motion of solid (Objectives 1-6) }\end{array}$} & S1. The concept of rotation & 1,8 \\
\hline & $\begin{array}{l}\text { S2. Determination and explanation of the } \\
\text { axis of rotation }\end{array}$ & 11 \\
\hline & S3. The concept of angular velocity & $2,9,12$ \\
\hline & $\begin{array}{l}\text { S4. The concept of linear (tangential } \\
\text { velocity) }\end{array}$ & 10 \\
\hline & S5. The concept of angular acceleration & 13,17 \\
\hline & S6. The concept of centripetal acceleration & 15,16 \\
\hline O2. Force torque (Objectives7) & S7. The concept of force torque & $4,6,7,14,22$ \\
\hline O3. Moment of inertia (Objective 8) & S8. The concept of moment of inertia & $3,25,27,32$ \\
\hline \multirow{2}{*}{$\begin{array}{l}\text { O4. Fundamental law of rotational } \\
\text { motion/Solid equilibrium (Objectives 9- } \\
\text { 10) }\end{array}$} & $\begin{array}{l}\text { S9. Understanding the Fundamental Law } \\
\text { of Rotational Motion }\end{array}$ & 18,2 \\
\hline & $\begin{array}{l}\text { S10. Understanding the balance of solid } \\
\text { bodies }\end{array}$ & 30,31 \\
\hline \multirow[t]{2}{*}{$\begin{array}{l}\text { O5. Angular momentum/ Conservation of } \\
\text { Angular momentum (Objectives 11-12) }\end{array}$} & $\begin{array}{l}\text { S11. Understanding the concept of angular } \\
\text { momentum }\end{array}$ & 21,28 \\
\hline & $\begin{array}{l}\text { S12. Understanding and applying the } \\
\text { principle of conservation of angular } \\
\text { momentum }\end{array}$ & 5,23 \\
\hline $\begin{array}{l}\text { O6. Work/Energy in rotational motion } \\
\text { (Objectives 13) }\end{array}$ & S13. Work/energy in rotational motion & $19,24,26,29$ \\
\hline O7. Rotational Motion (total) & & total \\
\hline
\end{tabular}

\section{DATA ANALYSIS}

\subsection{Quantitative analysis}

In the present case we consider the Exercise Group as an independent variable with two levels [1: Experimental Group (PO) and 2: Control Group (OE)] and as a dependent variable we consider the answers of the participants concerning the thirty-two (32) questions in the research tool. The categories and subcategories per subject, as well as the questions corresponding to each category and subcategory, are those listed in Table 1.

In order to investigate the performance of the students per teaching objective of the main category of both groups, during the post-testing, we will formulate hypotheses.

The research hypotheses are formulated as follows:

Null hypothesis $\boldsymbol{H}_{0}$ : The value distributions of the factor Oi - Student Performance of the populations per subject, from which the two samples come from (Experimental and Control Team) are exactly the same during the post-testing process $\left(\mu_{\mathrm{oi}}=\mu_{1 \mathrm{i}}\right)$.

Alternative hypothesis $\boldsymbol{H}_{I}$ : The value distributions of the factor Oi - Student Performance of the populations per subject from which the two samples come from (Experimental and Control Team) differ in their average during the post-testing process $\left(\mu_{\mathrm{oi}} \neq \mu_{1 \mathrm{i}}\right)$.

The diagram in Figure 6 shows the errors for the participating research groups of students in the post-testing process. From the diagram of fig. 6 we conclude that there is a significant difference between the two groups for the factors of the teaching objectives of the main category O1, O3, O6, O7: (a) Axes of rotation, angular/linear velocity, angular/linear acceleration, b) Moment of inertia, c) Work-energy in rotational motion and d) Rotational motion), as the respective overlaps are greater than half the average margin of error, while for the other factors they are not. 


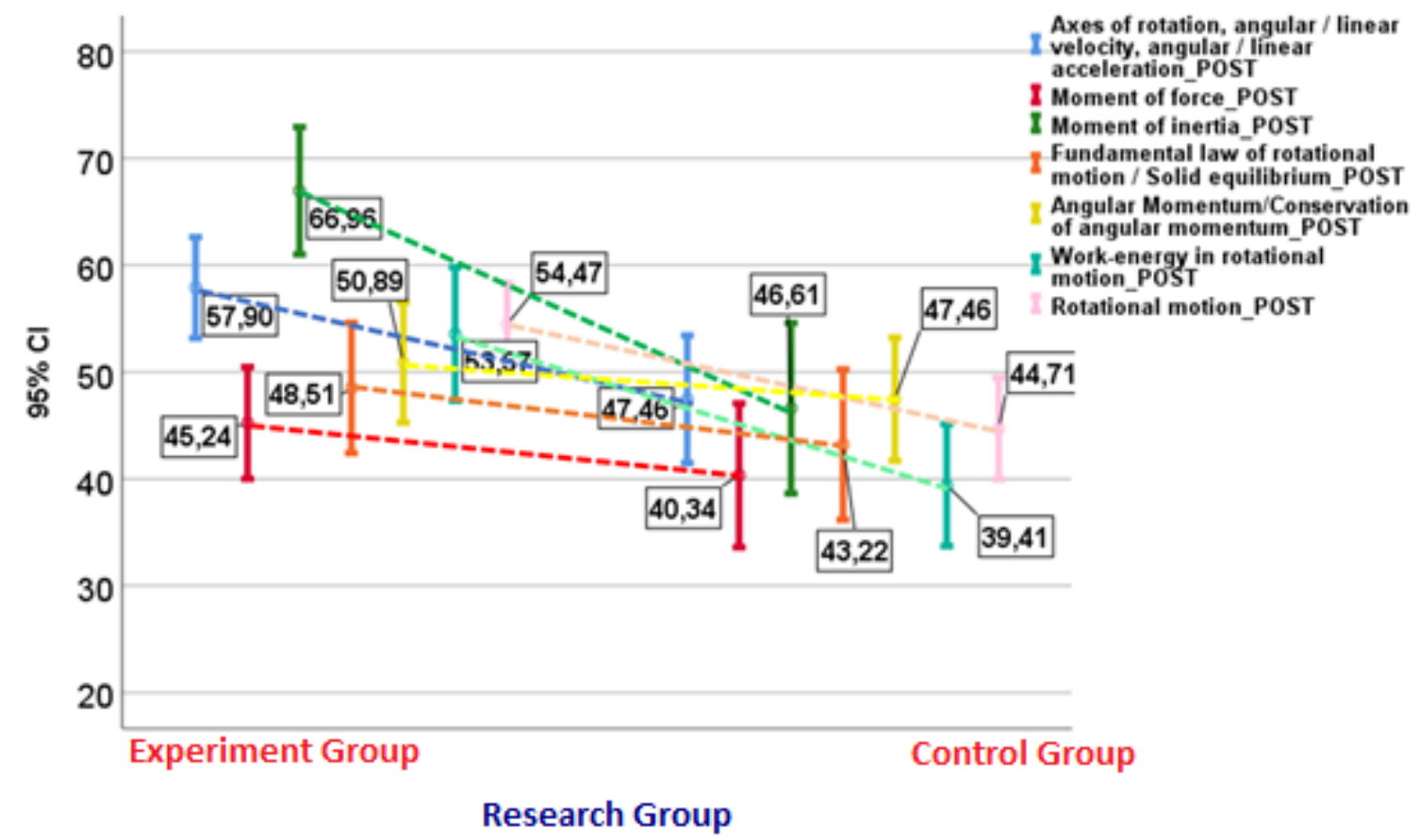

Figure 6. Error chart for the participating groups, comparing pre-test and post-test

In order to investigate the performance of the students of the two groups [1: Experimental Group (PO) and 2: Control Group (OE)] in the teaching subject per secondary teaching objective (Si i $=1,2 \ldots, 7)$, the non-parametric Mann-Whitney $\mathrm{U}$ criterion for independent samples was used.

The research hypotheses are formulated as follows:

Null hypothesis H0: The value distributions of the Student Performance factor of the populations in the subject per secondary subject (subcategories of the main subject $\mathrm{Oi}$ ) $\mathrm{Sj}$, from which the two samples (Experimental and Control Group) come, are exactly the same during the post-testing process $(\mu \mathrm{oj}=\mu 1 \mathrm{j})$.

Alternative hypothesis H1: The value distributions of the Student Performance factor of the populations in the subject per secondary teaching objective (subcategories of the main teaching objective $\mathrm{Oi}$ ) $\mathrm{Sj}$, from which the two samples (Experimental and Control Group) come from, differ in their average post-testing process ( $\mu \mathrm{oi} \neq \mu 1 \mathrm{i})$.

The results of the Mann-Whitney criterion of the average of each team ranking [Average] and the sum of the scores [Sum of places], as well as the data on the mean and standard deviation, are shown in Table 4.4.

Table 4: Results of the Mann-Whitney criterion of the mean of each group hierarchy [Mean Rank] and the sum of the hierarchies [Sum of Ranks], as well as data on mean and standard deviation and Inductive statistics (p-value) value)

\begin{tabular}{|c|c|c|c|c|c|c|c|c|}
\hline \multirow[b]{2}{*}{ Gravamen } & \multicolumn{5}{|c|}{ Ranks } & \multicolumn{2}{|c|}{$\begin{array}{c}\text { Descriptive } \\
\text { Statistics }\end{array}$} & \multirow{2}{*}{$\begin{array}{c}\text { Inductive } \\
\text { Statistics } \\
\text { p-value }\end{array}$} \\
\hline & $\begin{array}{c}\text { Subcategory / Sub- } \\
\text { objective }\end{array}$ & $\begin{array}{l}\text { Research } \\
\text { group }\end{array}$ & $\mathbf{N}$ & $\begin{array}{l}\text { Mean } \\
\text { Rank }\end{array}$ & $\begin{array}{l}\text { Sum of } \\
\text { Ranks }\end{array}$ & Mean & $\begin{array}{c}\text { Std. } \\
\text { Deviation }\end{array}$ & \\
\hline \multirow{7}{*}{ 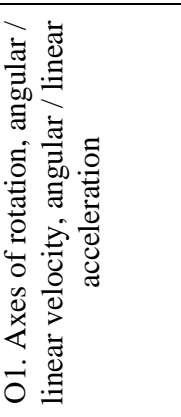 } & \multirow{2}{*}{$\begin{array}{l}\text { S1. The Concept of } \\
\text { rotation }\end{array}$} & EG & 84 & 76,81 & 6452,00 & 63,10 & 4,07 & \multirow[t]{2}{*}{0,046} \\
\hline & & $\mathrm{CG}$ & 59 & 65,15 & 3844,00 & 51,69 & 4,98 & \\
\hline & $\begin{array}{l}\text { S2. Determination and } \\
\text { explanation of the axis } \\
\text { of rotation }\end{array}$ & $\begin{array}{l}\text { EG } \\
\text { CG }\end{array}$ & $\begin{array}{l}84 \\
59\end{array}$ & $\begin{array}{l}80,41 \\
60,03\end{array}$ & $\begin{array}{l}6754,50 \\
3541,50\end{array}$ & $\begin{array}{l}60,71 \\
32,20\end{array}$ & $\begin{array}{l}5,36 \\
6,14\end{array}$ & 0,001 \\
\hline & \multirow{2}{*}{$\begin{array}{l}\text { S3. The concept of } \\
\text { angular velocity. }\end{array}$} & EG & 84 & 72,82 & 6116,50 & 50,79 & 2,96 & \multirow[t]{2}{*}{0,765} \\
\hline & & $\mathrm{CG}$ & 59 & 70,84 & 4179,50 & 48,59 & 3,81 & \\
\hline & \multirow{2}{*}{$\begin{array}{l}\text { S4. The concept of } \\
\text { linear (tangential } \\
\text { velocity) }\end{array}$} & EG & 84 & 79,58 & 6685,00 & 83,33 & 4,09 & \multirow[t]{2}{*}{0,001} \\
\hline & & $\mathrm{CG}$ & 59 & 61,20 & 3611,00 & 57,63 & 6,49 & \\
\hline
\end{tabular}




\begin{tabular}{|c|c|c|c|c|c|c|c|c|}
\hline & \multirow{2}{*}{$\begin{array}{l}\text { S5. The concept of } \\
\text { angular acceleration }\end{array}$} & EG & 84 & 74,63 & 6269,00 & 60,12 & 4,04 & \multirow[t]{2}{*}{$\mathbf{0 , 0 3 3}$} \\
\hline & & CG & 59 & 68,25 & 4027,00 & 54,24 & 4,73 & \\
\hline & \multirow{2}{*}{$\begin{array}{l}\text { S6. The concept of } \\
\text { centripetal acceleration }\end{array}$} & EG & 84 & 76,32 & 6410,50 & 47,02 & 3,91 & \multirow[t]{2}{*}{0,107} \\
\hline & & CG & 59 & 65,86 & 3885,50 & 37,29 & 4,62 & \\
\hline \multirow{2}{*}{ ช่ } & \multirow{2}{*}{$\begin{array}{l}\text { S7. The concept of } \\
\text { force torque }\end{array}$} & EG & 84 & 75,24 & 6320,00 & 45,24 & 2,63 & \multirow[t]{2}{*}{0,251} \\
\hline & & CG & 59 & 67,39 & 3976,00 & 40,34 & 3,37 & \\
\hline \multirow{2}{*}{ ஸे } & \multirow{2}{*}{$\begin{array}{l}\text { S8. The concept of } \\
\text { moment of inertia }\end{array}$} & EG & 84 & 82,86 & 6960,00 & 66,96 & 3,00 & \multirow[t]{2}{*}{$<0,001$} \\
\hline & & CG & 59 & 56,54 & 3336,00 & 46,61 & 4,03 & \\
\hline \multirow{4}{*}{ 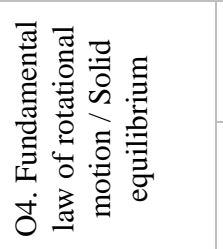 } & \multirow{2}{*}{$\begin{array}{l}\text { S9. Understanding the } \\
\text { Fundamental Law of } \\
\text { Rotational Motion }\end{array}$} & EG & 84 & 72,35 & 6077,00 & 39,29 & 3,79 & \multirow[t]{2}{*}{0,986} \\
\hline & & CG & 59 & 71,51 & 4219,00 & 38,14 & 4,25 & \\
\hline & \multirow{2}{*}{$\begin{array}{l}\text { S10. Understanding the } \\
\text { balance of solid bodies }\end{array}$} & EG & 84 & 76,29 & 6408,50 & 57,74 & 3,93 & \multirow[t]{2}{*}{$\mathbf{0 , 0 3 1}$} \\
\hline & & CG & 59 & 65,89 & 3887,50 & 48,31 & 4,35 & \\
\hline \multirow{4}{*}{ 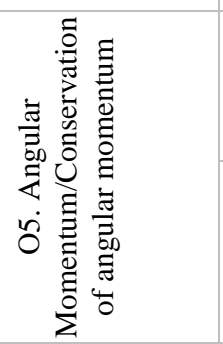 } & \multirow{2}{*}{$\begin{array}{l}\text { S11. Understanding the } \\
\text { concept of angular } \\
\text { momentum. }\end{array}$} & EG & 84 & 75,60 & 4460,50 & 39,83 & 3,97 & \multirow[t]{2}{*}{0,330} \\
\hline & & CG & 59 & 69,47 & 5835,50 & 35,12 & 3,57 & \\
\hline & \multirow{2}{*}{$\begin{array}{l}\text { S12. Understanding } \\
\text { and applying the } \\
\text { principle of } \\
\text { conservation of angular } \\
\text { momentum. }\end{array}$} & EG & 84 & 77,45 & 6506,00 & 66,67 & 3,53 & \multirow[t]{2}{*}{0,038} \\
\hline & & CG & 59 & 64,24 & 3790,00 & 55,08 & 4,31 & \\
\hline \multirow{2}{*}{ 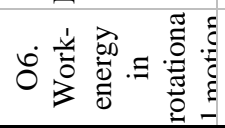 } & \multirow{2}{*}{$\begin{array}{l}\text { S13. Work / energy in } \\
\text { rotational motion. }\end{array}$} & EG & 84 & 80,94 & 6799,00 & 53,57 & 3,14 & \multirow[t]{2}{*}{0,001} \\
\hline & & CG & 59 & 59,27 & 3497,00 & 39,41 & 2,85 & \\
\hline
\end{tabular}

From the comparison of the average hierarchies for the factors we are interested in, we conclude that there are factors with significant differences between them in the Mean Rank, such as:
a) S1. The concept of rotation
b) S2. Determination and explanation of the axis of rotation
c) S4. The concept of linear (tangential velocity)
d) S5. The concept of angular acceleration
e) S8. The concept of moment of inertia
f) S10. Understanding the balance of solids
g) S12. Understanding and applying the principle of conservation of torque
h) S13. Work/energy in rotational motion,

which are statistically significant, as shown by the use of the non-parametric Mann-Whitney U independent sample previously. There are also factors with insignificant differences in the Mean Rank, such as:
a) S3. The concept of angular velocity
b) S6. The concept of centripetal acceleration
c) S7. The concept of force torque
d) S9. Understanding the Fundamental Law of Rotational Motion
e) S11. Understanding the concept of torque,

which are statistically insignificant, as demonstrated by the use of the non-parametric Mann-Whitney U independent sample above.

The analysis of the answers in the pre and post-test, as mentioned in the above tables, showed that, between the groups in the post-test, there is a significant difference between the experimental group E. G. and the control team C.G. (conventional teaching), which leads to an understanding that the didactic approach with simple custom/self-made 
experimental devices seems to be the most effective teaching method for the specific teaching goal and for the specific group of students.

\subsection{Qualitative analysis}

In this section we present the results of the findings from the discussions among the randomly selected twelve students from the experimental group.

The focus group participated in three rounds of discussions. The first three rounds were about the following issues:

- What they knew about the basic concepts of rotating solids around a fixed axis before the experiment, and what they learned after the experiment.

- What they think of the experimental device that uses the Raspberry Pi and the Hall Effect sensor.

- To express their general opinion on the interdisciplinary STEM didactic approach used to teach science concepts In the fourth round, participants were invited to work in groups and report the results of the discussions to the plenary. The dialogues of the discussions were recorded throughout the sessions, transcribed and categorized by teaching goal, following the structure of table 2 . The responses from the discussions were analyzed using the content analysis method.

The findings of the discussions show students' difficulties in understanding concepts of rotational motion, such as force, force torque and rotation. Indicatively, we mention students' alternative ideas before their participation in the experimental group: “...every force acting on an object produces torque...", “... 'Torque' is the same as 'force' and has the same direction...". The above comply with the results of Klammer (1998) research. Additionally, several students considered that "... constant torque produces constant angular velocity..." a view that is in line with the research findings of Rimoldini \& Singh (2005). Difficulties in understanding were also found in the concept of rotation and specifically in the pre-existing perceptions that "... Objects that move in a straight line do not have a torque..." and that "... 'torque' is not a vector quantity...".

These findings are consistent with what Palmieri \& Strauch (1963) report in their research. The students in this research talked about the easiness of use of the Raspberry Pi and its connection to the sensor and the laptop. One student said: "I see how important is its usefulness in angular velocity measurements for further calculation of the moment of inertia of the rotating solid".

As for the experimental process, one student stated "it would be good to use experimental devices with selfconstructions and approaches with STEM activities in physics, where possible, because they help to understand physics concepts".

Finally, in terms of approaching physics concepts through the STEM interdisciplinary approach, all participants reported that the experiments helped them to understand concepts that were "confusing" to them. For instance, a student stated: "Mathematics and physics lessons present difficulties, but with the use of custom/self-made constructions and technologies, the lesson becomes more enjoyable, more original and helps even the weakest students to cope with the difficulties of understanding these lessons".

\section{CONCLUSIONS}

This study was conducted to identify the effects of the STEM interdisciplinary approach on the understanding of concepts of a solid body rotation around a fixed axis of rotation. The results of the qualitative and quantitative analyses show that the experimental group, that used the experimental devices, had better results in understanding the concepts for the four out of the six main teaching objectives and specifically in the $\mathrm{O} 1$ axes. Characteristic quantities of the rotational motion of solids, O3. Moment of inertia., O6. Work-energy in rotational motion, O7. Rotational Motion (total). As for the secondary teaching objectives, from the total of thirteen objectives, we had a significant improvement in eight of them, and specifically in: S1. The Concept of rotation, S2. Determination and explanation of the axis of rotation, S4. The concept of linear (tangential velocity), S5. The concept of angular acceleration, S8. The concept of moment of inertia, S10. Understanding the balance of solid bodies, S12. Understanding and applying the principle of conservation of angular momentum. S13. Work/energy in rotational motion.

This research was conducted with high school students, aged 16-17 and showed that the teaching approach through STEM activities brings better results in understanding physics concepts and therefore the natural world around us. The results of the research are the same as those of Wade-Shepherd (2016), who found that students who attended a STEM training program had a significantly higher performance in mathematics and science than those who attended the curriculum through conventional teaching. Acar et al. (2018) came up with the same results for primary school students, and discussed the positive effects of the STEM teaching approach for mathematics and science. Furthermore, in his research for secondary school students, Olivarez (2012) had come to the same conclusions by recording the effects of the STEM interdisciplinary approach on mathematics and science.

The qualitative analysis showed that the teamwork in the experimental group had a positive effect on the students, during the STEM activities, as they collaborated with one another to make joint decisions. The participants also expressed their desire to use STEM activities in the teaching of science concepts, wherever and whenever possible, as in their opinion, this has added didactic value to their learning. 


\section{REFERENCES}

[1] Acar, D., Tertemiz, N., Taşdemir, A. The Effects of STEM Training on the Academic Achievement of 4th Graders in Science and Mathematics and their Views on STEM Training. International Electronic Journal of Elementary Education, vol. 10 no.4, pp 505-513, 2018.

[2] Abdisa, G., Getinet, T. The effect of guided discovery on students' Physics achievement. Journal of Physics Education, vol. 4, no 6, pp 530-537, 2012.

[3] Brown, D. E., Clement, J. Overcoming misconceptions via analogical reasoning: Abstract transfer versus explanatory model construction. Instructional science, vol 18, no. 4 , pp 237-261, 1989.

[4] Carvalho, P. S., Sousa, A. S. Rotation in secondary school: teaching the effects of frictional force. Physics education, vol. 40, no.3, pp 257, 2005.

[5] Close, H. G., Gomez, L. S., Heron, R. L. Student understanding of the application of Newton's Second Law to Rotating Rigid Bodies. Physics Education Research Section,vol 81, no.6, pp.458-470, 2013.

[6] Cohen, L., Manion, L., \& Morrison, K. (2008). Methodology of educational research. Athens: Metaichmio. [In Greek].

[7] Eshetu, F., Assefa, S. Effects of context-based instructional approaches on students' problem-solving skills in rotational motion. EURASIA Journal of Mathematics, Science and Technology Education, 15(2), em1665, 2018.

[8] Etkina, E. Millikan award lecture: Students of physics-Listeners, observers, or collaborative participants in physics scientific practices? , 2015.

[9] Hewson, P. W. Conceptual change in science teaching and teacher education. In a meeting on "Research and Curriculum Development in Science Teaching," under the auspices of the National Center for Educational Research, Documentation, and Assessment, Ministry for Education and Science, Madrid, Spain, 1992.

[10] Yuliati, L., Yogismawati, F., Nisa, I. K. Building scientific literacy and concept achievement of physics through inquiry-based learning for STEM education. In Journal of Physics: Conference Series (Vol. 1097, No. 1, p. 012022). IOP Publishing, 2018.

[11] Klammer, J. An Overview of Techniques for Identifying, Acknowledging and Overcoming Alternate Conceptions in Physics Education, 1998.

[12] Leyvraz, F. Understanding Rigid Body Motion in Arbitrary Dimensions. European Journal of Physics, vol. 36, no. 3, pp.1-17, 2015.

[13] Mashood, K. K, Singh, V. A. An inventory on rotational kinematics of a particle: unravelling misconceptions and pitfalls in reasoning. European Journal of Physics, vol, 33,no, 5, pp. 1301-1312, 2012.

[14] Mashood, K. K., \& Singh, V. A. Variation in angular velocity and angular acceleration of a particle in rectilinear motion. European Journal of Physics, vol. 33 , pp.473-78,2012.

[15]Nachimuthu, K., \& Vijayakumari, G. Perceptions on Multimedia Technology by Collage of Educational Teachers. Journal of Education and Learning, vol. 6,no. 3, pp. 167-176,2012.

[16] Nicol, D. J., \& Macfarlane-Dick, D. Formative assessment and self-regulated learning: A model and seven principles of good feedback practice. Studies in higher education, vol.31, no. 2, pp.199-218, 2006.

[17] Olivarez, N. The Impact of a STEM program on academic achievement of eighth grade students in a south Texas middle school (Doctoral dissertation, Texas A\&M University-Corpus Christi), 2012

[18] Palmieri, J., \& Strauch, K. An experiment on angular momentum for the introductory laboratory. American Journal of Physics, vol. 31, no.2, pp. 91-95, 1963.

[19] Pol, H. J., Harskamp, E. J., Suhre, C. J., Goedhart, M. J. The effect of hints and model answers in a student-controlled problem-solving program for secondary physics education. Journal of Science Education and Technology, vol.17,no. 4, pp.410-425,2008.

[20] Pranata, O. D., Yuliati, L., Wartono. Concept acquisition of rotational dynamics by interactive demonstration and freebody diagram. Journal of Education and Learning,vol.11,no.3, pp. 291-298,2017.

[21] Rafon, J., \& Mistades, V. Interactive Engagement in Rotational Motion via Flipped Classroom and 5E Instructional Model [J]. International Journal of Information and Education Technology, vol.10, no.12, pp.905-910, 2020. 
[22] Rimoldini, L. G., Singh, C. Student understanding of rotational and rolling motion concepts., $\sigma \sigma$. Physical Review Special Topics-Physics Education Research, 1(1), 010102, 2005.

[23] Robinson, S. J. Connecting the mathematical and conceptual views of angular momentum. Physics Education, vol.49, no. 2, pp 144, 2014.

[24] Sarığlan, A. B., Küçüközer, H. Determination of conceptions of secondary 10th grade students about torque, angular momentum and Kepler's 2nd law, 2013.

[25] Terry, C., Jones, G., Hurford, W. Children's conceptual understanding of forces and equilibrium. Physics Education, vol.20, pp. $162-165,1985$.

[26] Tsihouridis, Ch., Vavougios, D., \&. Ioannidis, G., S. Students designing their own experiments on heat transfer phenomena using sensors and ICT: An educational trial to consolidate related scientific concepts. International Journal of Emerging Technologies in Learning, iJET, ISSN: 1863-0383, Vol 4, pp 74-82, 2009.

[27] Tsihouridis Ch., Vavougios D., Ioannidis G., Paraskeuopoulos S. Specially designed sound-boxes used by students to perform school-lab sensor-based experiments, to understand sound phenomena. International Journal of Online Engineering (iJOE), Vol 7, no 1, pp 25-32, 2011, ISSN 1868-16-46. ISSN: 1861-2121

[28] Tsihouridis, C., Vavougios, D., Ioannidis, G. The effectiveness of virtual laboratories as a contemporary teaching tool in the teaching of electric circuits in Upper High School as compared to that of real labs. Proceedings of the 2013 International Conference on Interactive Collaborative Learning (ICL), 25-27 September 2013, Kazan National Research Technological University, Kazan, Russia ISBN : 978-1-4799-0152-4/13/\$31.00 @2013 IEEE, pp. 816-820.

[29] Tsihouridis, C., Vavougios, D., Ioannidis, G. Alexias, A. Using sensors and data loggers in an integrated mobile school-lab setting to teach Light and Optics. Proceedings of the 2014 International Conference on Interactive Collaborative Learning (ICL), 03-06 September 2014, Dubai UAE, United Arab Emirates Russia ISBN : 978-1-47994437-8/14/\$31.00 @2014 IEEE, pp. 439-445.

[30] Wade-Shepherd, A.A. The effect of middle school STEM curriculum on science and math achievement scores, 2016.

[31] Wang, H. H., Moore, T. J., Roehrig, G. H., Park, M. S. STEM integration: Teacher perceptions and practice. Journal of Pre-College Engineering Education Research (J-PEER),vol.1,no.2, pp.2,2011.

[32] Widolo, A., Duit, R., Muller, C. Constructivist views of teaching and learning in practice: teachers' views and classroom behavior. In Annual meeting of the national Association for Research in Science Teaching,2002.

[33] Williamson, J. C., Torres-Isea, R.O., Kletzing, C. A. Analyzing linear and angular momentum conservation in digital videos of puck collisions. American Journal of Physics, vol. 68, no. 9, pp. 841-847,2000. 